\title{
An Investigation into the Use of Net-Conferencing Groupware in Simulation Modelling
}

\author{
Simon J. E. Taylor ${ }^{1}$, Stewart Robinson ${ }^{2}$ and John Ladbrook ${ }^{3}$ \\ ${ }^{1}$ Centre for Applied Simulation Modelling, Brunel University, Uxbridge, UK \\ ${ }^{2}$ Warwick Business School, Warwick University, Coventry, UK \\ ${ }^{3}$ Dunton Engineering Centre, The Ford Motor Company, Basildon, UK
}

Simulation modellers are major users of software tools. Advances in computing such as collaborative working tools and distributed technologies have created new possibilities for innovation in simulation modelling. Collectively, we address these as Collaborative Support for Simulation Modelling (CSSM). To contribute to CSSM, we consider the problem of whether or not it is possible to support human-to-human collaboration in simulation modelling through the use of commonly available groupware technology. The paper reviews aspects of human-to-human collaboration in the simulation modelling process and introduces an example of commonly available groupware technology, the net-conferencing groupware tool NetMeeting ${ }^{\circledR}$. Results of a survey into the perceived use of NetMeeting ${ }^{\circledR}$ in simulation and some resulting applications of the net-conferencing tool that have emerged are presented.

Keywords: simulation, groupware, Collaborative Support for Simulation Modelling, NetMeeting.

\section{Introduction}

Simulation modellers are major users of software tools, since these tools are required to support the process of simulation modelling and analysis $[1,2]$. However, advances in computing such as collaborative working tools (groupware) and distributed technologies (e.g. the Internet and the World Wide Web) have created new, and so far unexploited, possibilities for innovation in simulation modelling and the creation of new tools and facilities that could improve the productivity of simulation. The goals of this work are, therefore, to attempt to investigate the effective technology transfer of this distributed systems technology in simulation modelling with respect to industry. Research topics include the support of human-tohuman collaboration (computer supported cooperative work/groupware and simulation) and the support of computer-to-computer collaboration (distributed simulation, parallel and distributed simulation, and web-based simulation). Collectively, we address these as Collaborative Support for Simulation Modelling (CSSM).

To contribute specifically to CSSM, and to the wider simulation modelling community, we consider the problem of whether or not it is possible to support human-to-human collaboration in simulation modelling through the use of commonly available groupware technology. To this end, this paper is structured as follows. In Section 2 we review some of the aspects of the role of human-to-human collaboration in the simulation modelling process. Section 3 introduces an example of commonly available groupware technology, the net-conferencing groupware tool NetMeeting ${ }^{\circledR}$. Section 4 presents some results of a survey into the perceived use of NetMeeting ${ }^{\circledR}$ in simulation and some applications of the net-conferencing tool that have emerged post-survey. Finally, section 5 concludes the paper with some future directions for this work. 


\begin{tabular}{lll}
\hline Ormerod's Role & Role in a Simulation Study & Responsibility of the Role \\
\hline Doers & Project manager & $\begin{array}{l}\text { Responsible for the managing the process; } \\
\text { may not have specific modelling skills } \\
\text { Develops the model (conceptual and } \\
\text { computer) }\end{array}$ \\
Modeller & Clients & $\begin{array}{l}\text { Experiments with the model to obtain un- } \\
\text { derstanding and looks for solutions to the } \\
\text { real world problem }\end{array}$ \\
\hline Done for & Data providers & $\begin{array}{l}\text { The problem owner and recipient of the re- } \\
\text { sults; directly or indirectly funds the work } \\
\text { Recipients of the model }\end{array}$ \\
\hline Modelling supporter & $\begin{array}{l}\text { Subject matter experts who are able to pro- } \\
\text { vide data and information for the project } \\
\text { A third party expert (software vendor, con- } \\
\text { sultant or in-house expert) provides soft- } \\
\text { ware support and/or modelling expertise }\end{array}$ \\
\hline Done without & Managment, staff, customers & $\begin{array}{l}\text { Beneficiaries of the project, but not } \\
\text { involved; in some cases they are not aware } \\
\text { of the project }\end{array}$
\end{tabular}

Table 1. Roles in a Simulation Study.

\section{Communication and Collaboration in Simulation Modelling}

Before considering the problem of technological support for collaboration, we first review the role of communication and collaboration in simulation modelling. The need for regular communication and collaboration throughout the modelling process is generally agreed to be of significant importance $[3,4,5,6,7]$, as it is within project management more generally [8]. In a study of perceptions of the quality of simulation studies, Robinson [9] identifies three types of quality: quality of the content, quality of the process and quality of the outcome. The former two are the key determinants of the latter. In interviewing modellers and customers of simulation studies in a business context, he identifies that more than $75 \%$ of customer perceptions of quality depend upon the process, with less than $25 \%$ resting on the content. This is largely because customers have insufficient knowledge to judge content quality, and so depend upon other cues for their quality perceptions. Communication and collaboration are a major part of process quality [10]. This communication and collaboration needs to be between all who have some involvement in the study. It is possibly interesting to note that there has been some work on identifying the roles of those who take part in team working activities. To attempt to delve a little deeper into the effect that technology has on human-to-human collaborative support for simulation modelling, we introduce the notion of roles in simulation modelling.

\subsection{Roles in Simulation Modelling Studies}

Team roles have been widely researched in organisational behaviour $[11,12]$. There is, however, very little written on team roles in operational research or more specifically simulation studies. Mitchell [13] briefly touches upon the subject. Meanwhile, Ormerod [14] appears to provide one of the few useful classifications of team roles in operational research interventions:

- The doer: in this case the simulation modeller

- The done for: the clients

- The done with: members of the simulation modelling team

- The done to: those from whom information and data are obtained

- The done without: those not involved, but nevertheless with a vested interest in the outcome 


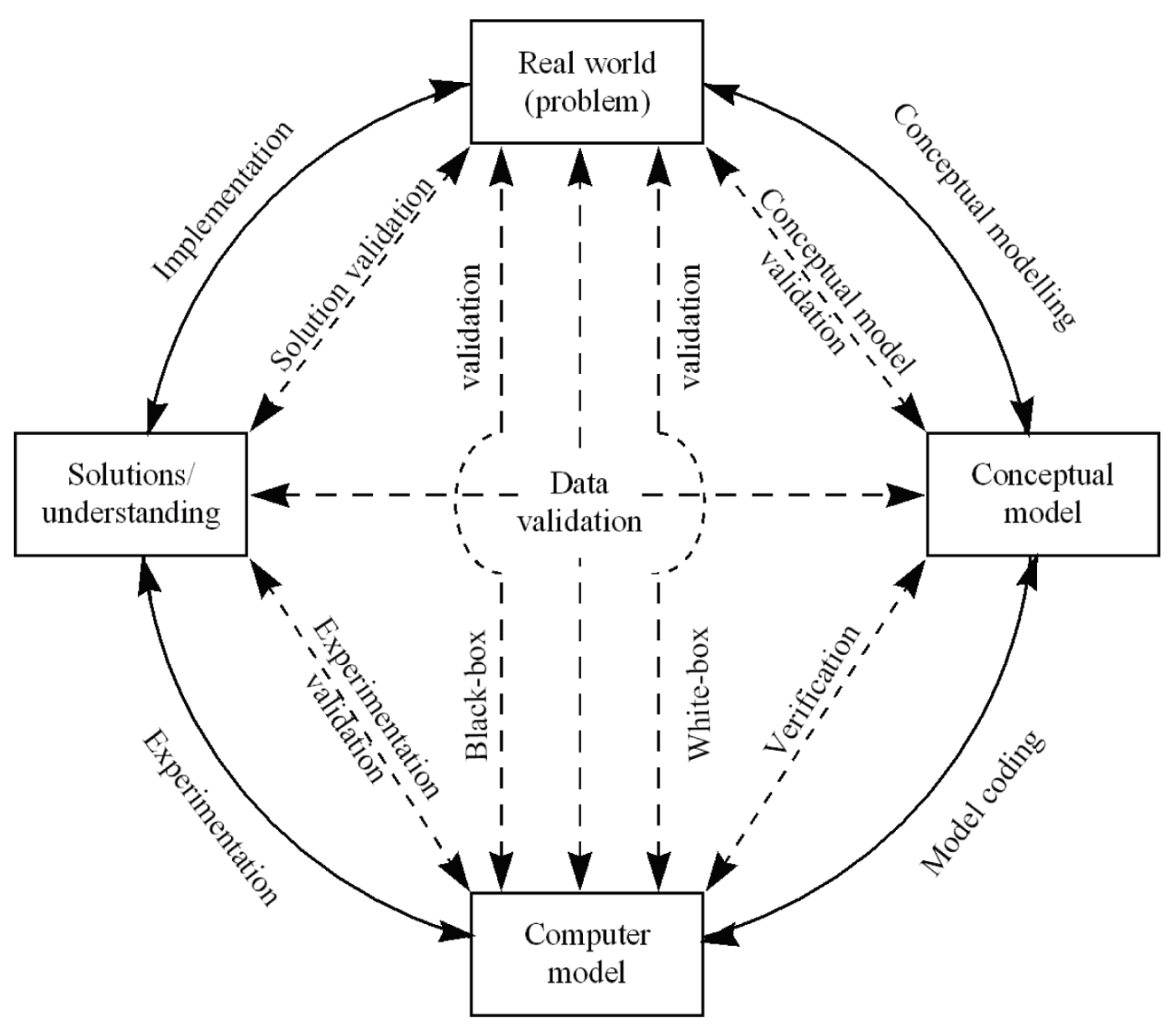

Fig. 1. The Simulation Modelling Process.[15]

Translating this into the specific context of a simulation study, a variety of roles is outlined in Table 1. It is important to note that these are roles rather than individuals. In other words, a person may take on more than one role, or many people may be required to share a single role. For instance, the modeller is often the project manager and the model user, in that $\mathrm{s} /$ he performs the experimentation. There may, however, be a number of people tasked with being data providers. Additionally, note that the model user appears twice in the list, first as a done for and second as a doer. In the early part of the project the model user is effectively a client, since the model is being developed for his/her use. In the latter part he/she turns doer, using the model to provide information to the organisation.

The first two roles have direct involvement in the project team; the third has some level of involvement, while the latter two (done to, done without) have little or no involvement. A wide group of people may need to be interviewed in order to obtain information about the system being modelled, but they do not need to have direct involvement in the simulation project. This is unlike the data providers who collect, analyse and provide information and so have a more active role to play, albeit that they are not necessarily central to the project team (hence they are described as done with rather than doers). There may be a great many beneficiaries of the project, some of whom are even unaware of its existence. Customers in a bank are probably not aware that a simulation model has been developed to improve the level of service offered. They are, nevertheless, beneficiaries. Additionally, these roles might be considered by some as being stakeholders in the simulation study (including, for example, the doer as s/he has a vested interested in an "economically" successful outcome).

\subsection{Communication and Collaboration Between the Roles}

The simulation modelling process can be described as a number of stages, as shown in Figure 1. Four key stages are performed in an 
iterative manner: conceptual modelling, model coding, experimentation and implementation. In parallel with each of these are various verification and validation processes. The level of communication and collaboration required in a simulation study is now discussed, considering the process set out in Figure 1 in the context of Ormerod's roles.

The nature and level of communication and collaboration between the simulation modellers and each of these roles will vary, and will depend upon the stage of the study that has been reached. Generally, the doer performs the simulation study interactively with the done for. Where additional help is needed from subject matter experts and for supporting the modelling effort, the done with become involved. Interaction is also required with appropriate done to roles to gain relevant information and data. The done without are not involved (their role and their effect on the simulation study is outside the scope of this paper).

During the simulation study, the frequency with which the roles interact is determined by the stage of the study. Consider a manufacturing system where a client wants to investigate the cost of manufacturing a new product with current production facilities. The client has enlisted a simulation modeller to help him make a decision (i.e. we assume a single modeller and not a team). To begin the simulation study, the real world problem must be identified and a conceptual model of the system being studied must be built. In this case the problem is to evaluate the cost of production. A conceptual model is needed to identify what system elements (scope) and detail (depth) must be simulated to investigate the problem. Conceptual modelling is an intensive activity, as the modeller must develop an understanding of the system being studied. The modeller and the client, as well as any appropriate information sources (i.e. personnel involved in the production process), must therefore interact frequently so that the modeller can accomplish this. The doer must interact frequently with the done for, done with and the done to. Indeed, it is during conceptual modelling that the level of communication and collaboration needs to be at its highest.

In model coding, the need for interaction is reduced. The modeller spends much time devel- oping the computer model away from the eyes of the other parties. Verification is performed largely in isolation, since the modeller checks the model against the design stated within the conceptual model. That said, white-box validation (a detailed check of the computer model against the real world) is performed at regular stages during model coding, and so the model needs to be presented to the other parties for critique. The same is also true for black-box validation (a check of the input to output behaviour of the model against the real world), which can only be performed once the model is believed to be complete. In terms of our study, the modeller would meet less frequently with the roles involved in the manufacturing system. The doer interacts moderately with the done with and the done to. Interaction with the done for is probably greater, since it is necessary to keep them appraised of progress.

Once the computer model is completed, the model user performs experiments with the clients to develop an understanding of how the complex relationships in the system being studied impact on the problem. In our case, experiments are performed with the computer model of the manufacturing system to understand the probable cost of the new product. Significant interaction is required between the model user and the clients in order to share the understanding gained from the experimentation and to direct the continuing experimentation. It is expected that there will be much communication and collaboration between the doer (now the model user) and the done for. The done with and certainly the done to will be needed to a much lesser degree, although the need for help and information is not completely removed during experimentation.

The final stage (of a cycle) in the study is implementation. This may entail implementing the solutions and/or understanding that have been developed from the experimentation. Apart from fully explaining the results from the experimentation, the doer often has little involvement in this form of implementation. That said, it is sometimes necessary to maintain the model or to provide results from further runs. In other circumstances, the model itself is implemented, that is, handed-over for continued use; for instance, if the model is to be used for real-time control. In this situation, there is a much greater 
need for communication and collaboration on an on-going basis during implementation.

While the requirement for communication and collaboration is determined by the stage in a simulation study, it is also determined by the nature of the simulation study. Robinson [16] identifies a continuum of modes of practice in simulation modelling. At one end is simulation as 'software engineering'. In such a mode the modeller is quite removed from the client, except during the definition phase of the work and in reporting results at the end. At the other extreme is simulation as 'facilitation', where the simulation is developed and used with the client in order to facilitate learning about the system under investigation. Here, constant communication and collaboration is required. In between, lies simulation as a 'process of organisational change'. This does not require the constant presence of the client, but regular interaction during each modelling stage is seen to be important.

In consideration of what contributes to successful simulation modelling, it is clear that communication and collaboration between a variety of roles is a key factor. While the volume of this might vary from study to study, communication and collaboration can add cost due to reasons such as meeting delays or significant travelling times. This is further exacerbated if those involved in the study are inconveniently or distantly located. It therefore appears that our problem of determining if it is possible to provide support for human-to-human collaboration in simulation modelling is a worthy one. To investigate this, in the next section we introduce groupware and an example of a commonly available groupware technology.

\section{Groupware and Microsoft's NetMeeting ${ }^{\circledR}$}

The previous section highlighted the need for human-to-human collaboration support in a simulation study. The field of Computer Supported Cooperative Work (CSCW) is a multidisciplined research area that draws on expertise from both social and technical disciplines, including distributed systems and internetworking, multimedia, communication, computer science and socio-organisational theory [17]. Research in CSCW has led to groupware, the prac- tical application of CSCW research, a technology that pervades (often without the user knowing) many computing applications (for example IBM's Lotus Notes and Microsoft Office products have several examples of groupware). There are specific groupware technologies to support specific tasks. These can be characterised as systems that support cooperative meetings or work as categorised by the groupware time/location matrix (Figure 2). The matrix divides groupware on the basis of time and location. During some task, people may meet at the same time, at different, but predictable times (shift working on a project) or at different, but unpredictable times (drop in team rooms). Similarly, people may meet in the same place (a room), in different, but known locations (different offices) or at different, but unpredictable locations (mobile workers). Note that many groupware technologies support activities that fall simultaneously into many of the groups. We now present one particular example of groupware technologies: the net-conferencing groupware Microsoft's NetMeeting ${ }^{\circledR}$. As we will see, this type of net-conferencing application supports groupworking between workers in different but predictable locations at the same time.

Microsoft's NetMeeting ${ }^{\circledR}$ is a commonly available net-conferencing tool that combines various aspects of tele- and video-conferencing (only two users) with information sharing applications such as text chat, whiteboard, file transfer and application sharing. Briefly, NetMeeting ${ }^{\circledR}$ requires two or more parties to be logged on simultaneously to communicate remotely. It conferences (links/shares) two or more parties working together on a particular task via a network (commonly the Internet). NetMeeting ${ }^{\circledR}$ works acceptably on a laptop connected to the internet via a normal modem (faster communications are preferable for ease of use). NetMeeting ${ }^{\circledR}$ is accessed either though the Start menu, via a menu in a Microsoft Office ${ }^{\circledR}$ application, or through Run by typing conf in the dialog box. The actual choice depends on the version of Microsoft Windows ${ }^{\circledR}$ being used. One of the observations of our work is that there appears to be evidence that the general knowledge of NetMeeting ${ }^{\circledR}$ is low in the simulation modelling community.

In terms of the time/location matrix, commonly available net-conferencing groupware such as 
Time

\begin{tabular}{|c|c|c|c|c|}
\hline & & Same & $\begin{array}{c}\text { Different, } \\
\text { but predictable } \\
\end{array}$ & $\begin{array}{c}\text { Different, } \\
\text { but unpredictable } \\
\end{array}$ \\
\hline \multirow{3}{*}{ Place } & Same & Meeting facilitation & Work shifts & Team rooms \\
\hline & $\begin{array}{l}\text { Different, but } \\
\text { predictable }\end{array}$ & Net-conferencing & Electronic mail & $\begin{array}{c}\text { Collaborative } \\
\text { writing }\end{array}$ \\
\hline & $\begin{array}{l}\text { Different, but } \\
\text { unpredictable }\end{array}$ & $\begin{array}{c}\text { Interactive } \\
\text { multicast seminars }\end{array}$ & $\begin{array}{c}\text { Computer bulletin } \\
\text { boards }\end{array}$ & Workflow \\
\hline
\end{tabular}

Fig. 2. Time/Location Matrix[12].

NetMeeting ${ }^{\circledR}$ is geared to the support of "synchronous" working rather than "asynchronous" working. Synchronous working can be thought of as being an on-going conversation between two or more people who participate solely in the same time conversation. Conversely, asynchronous working can be thought of as an ongoing conversation by email where the conversation is progressed at different times but participants take part in other discussions. The facilities of NetMeeting ${ }^{\circledR}$ (video-conferencing, tele-conferencing, text chat, application sharing, file transfer) all support the worker in same time interactions. The fact that the application is networked enables workers to interact remotely at different, but predictable locations (or at least addresses). NetMeeting therefore falls in the same time/different, but predictable location box of the time/location matrix.

Figure 3 shows an example screen shot of NetMeeting ${ }^{\circledR}$. The front end of the package is in the top left hand corner of the screen. The top part of the user interface displays the video feed (from a web cam) and the teleconferencing controls. The various buttons on display allow access to the different package functions (application sharing, text chat, whiteboard, and file transfer). The larger part of the screen shot is taken by a simulation application (in this case the simulation program is Visual Thinking International's Simul8 ${ }^{\circledR}$ with a simple job shop taken from the package's model library).

In Figure 4, the NetMeeting ${ }^{\circledR}$ window has been minimised to clear space. The Figure shows the text chat and whiteboard applications. Text chat allows users to interact via a text conversation. The Whiteboard application allows users to draw various shapes on a shared drawing space (effectively shared Microsoft Paint- brush $\left.^{\circledR}\right)$. Another application is File Transfer. This appears in a similar form to text chat; a menu of participants allows the user to choose to transfer a file to another single participant or to the entire complement of participants. The final, and possibly most powerful feature of this package is the application sharing feature. This allows a participant in a NetMeeting ${ }^{\circledR}$ session to share any application running on his or her computer. For example, a simulation package can be "shared" by selecting application sharing and selecting the simulation package from a list of running applications that NetMeeting ${ }^{\circledR}$ can find on that participant's computer. Once the package has been shared, all participants receive an image of the package as if it were running locally on their computer (the simulation package shown in Figures 3 and 4 is actually running on the computer of the other participant in the conferencing session). Each participant can see the shared package and the results of any manipulation performed by the owner of the package. For example, the owner may communicate to the other participants (by text chat for example) that $\mathrm{s} / \mathrm{he}$ is going to run the model to demonstrate how a part of the model works. The owner runs the model as usual and the other participants will see the model animation as if the package were running on their own computers (with the caveat of communication speed). If one of the participants wants to point out a model feature, or indeed stop the model and change some aspect of the model, the participant can request control from the owner. If control is granted, then all participants will see the mouse arrow annotated with the ID of the participant. The participant is then in direct control of the package running on the remote machine of the owner and may modify the model as they wish. 


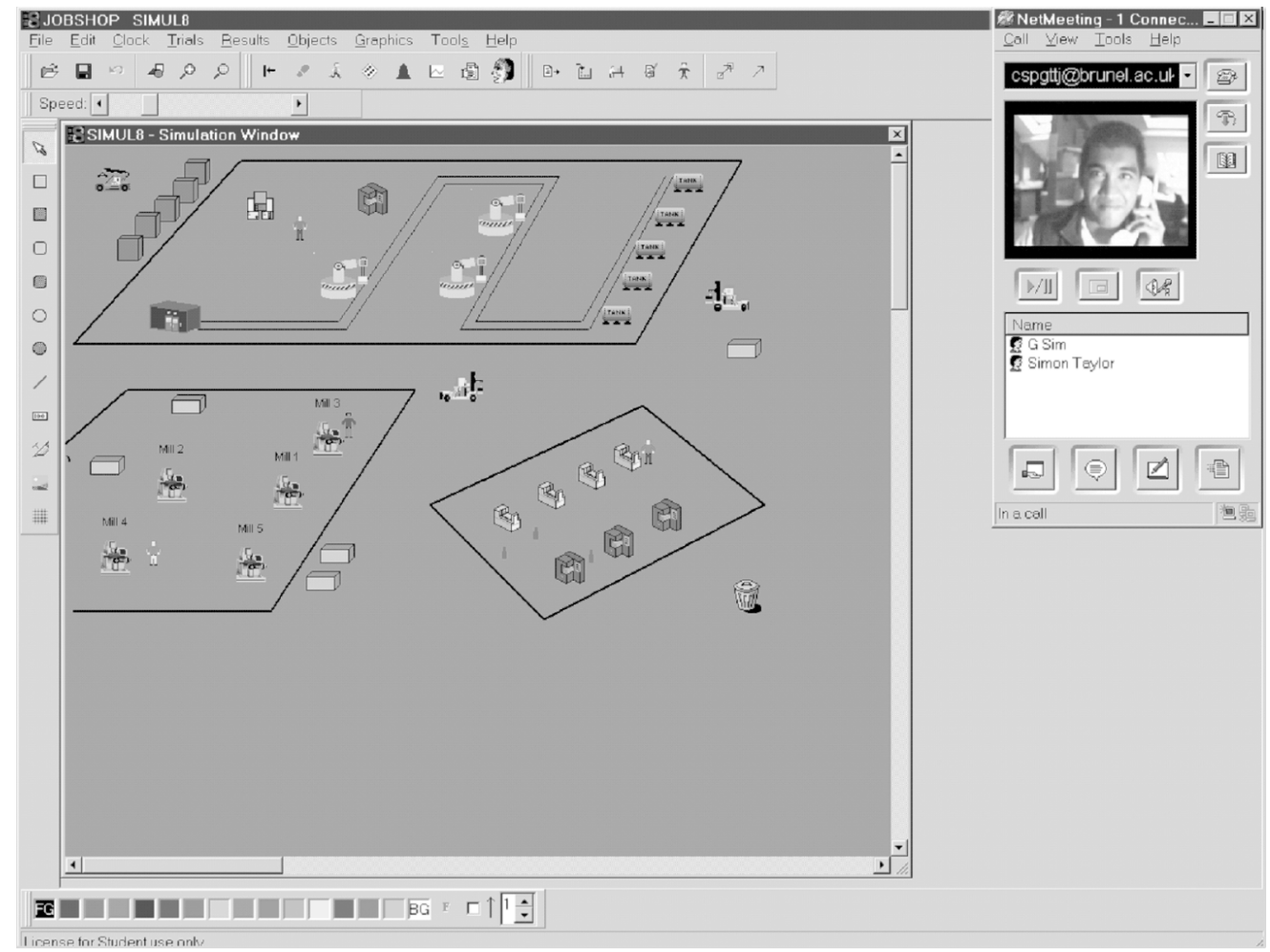

Fig. 3. Microsoft's NetMeeting with Simulation Tool.

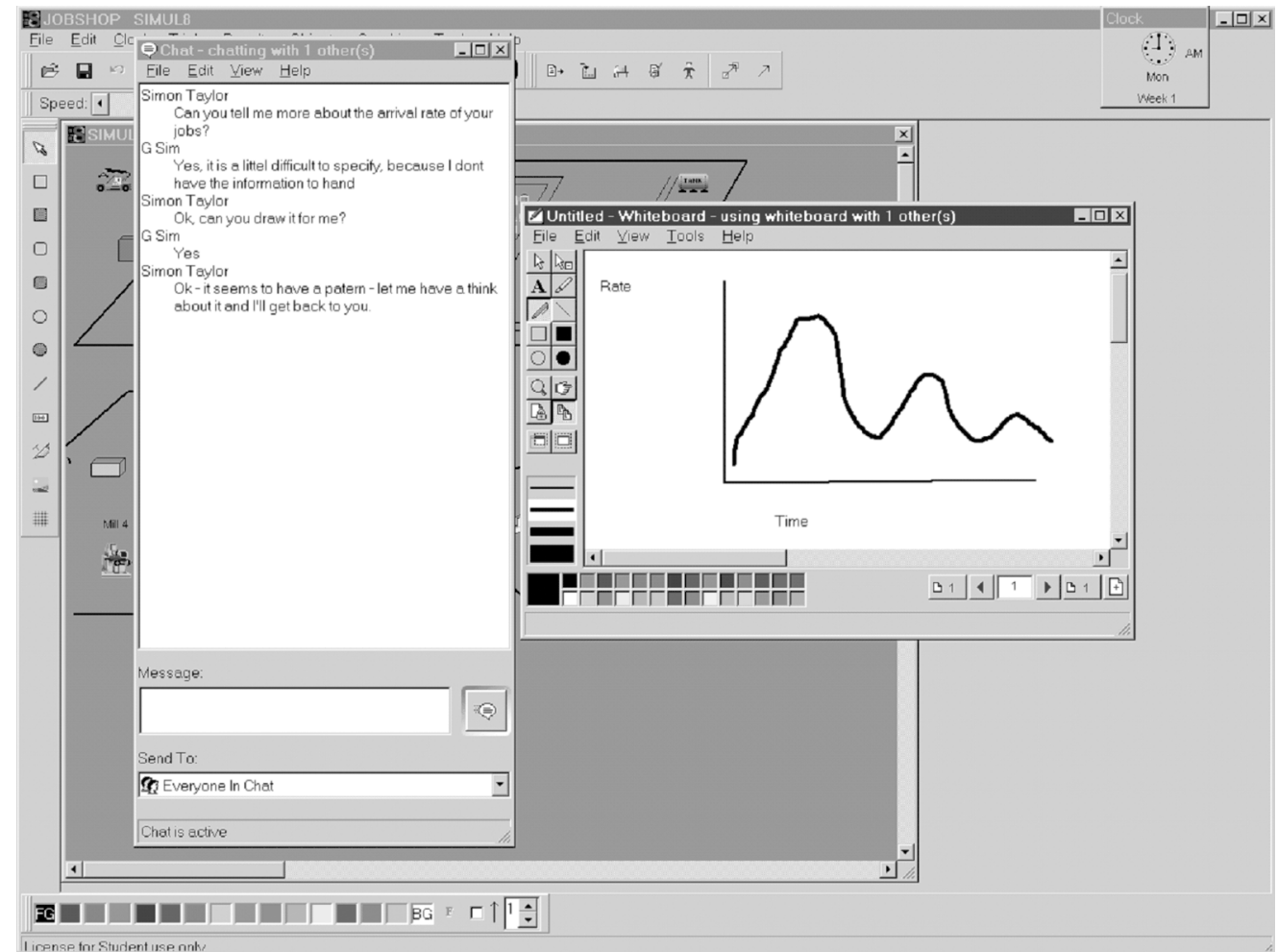

Fig. 4. Text Chat and Whiteboard Features of NetMeeting. 
The next section discusses some experiences in the evaluation of the NetMeeting ${ }^{\circledR}$ groupware in support of human-to-human collaboration in simulation modelling.

\section{Evaluation}

The approach taken for evaluation had two stages. The first stage invited participants to take part in a "standard" demonstration of NetMeeting ${ }^{\circledR}$ and then in a follow up with a questionnaire that invited participants to consider how potentially useful they might find this application in their role as a simulation modeller. The second stage was to visit the participants two to three months later to see how (if any) adoption of the software was progressing. During the two to three month gap, the staff at Brunel University provided user support in the implementation of NetMeeting ${ }^{\circledR}$ facilities at a participant site. The staff were restricted to the user support role. Care was taken to ensure that the staff did not introduce new ideas and experience into the process - our objective was to examine the individual innovation made by a participant and not that given by shared experience.

\subsection{Stage 1}

In the first stage, the demonstration was provided at nine different sites to approximately seventy subjects (one site involved a workshop led by the Simulation Study Group of the UK Operational Research Society). Eleven returns were made from users in industry, defence, and academia. The results are presented here therefore as an indication rather than exhaustive evidence.

The demonstration took the form of an example of collaboration between two users (the modeller doer and the system owner done for). A laptop with NetMeeting ${ }^{\circledR}$ was connected via a standard modem to a global NetMeeting server. Each of the groupware features was demonstrated in turn with application sharing left for last. The voice communication mechanism used was telephone (mobile) rather than the audio feature of NetMeeting. This was due to feedback when audio was placed on external speakers (necessary for the demonstration).
The evaluation of audio was therefore on the basis of telephone (in two cases conference calls). The most unpredictable element of the exercise was making the modem connection, as various methods were used each time to find an appropriately working phone point. The video image that was shown was quite jerky. It was pointed out that this would be smooth if a high speed connection to the Internet was used, rather than via a lower speed $56 \mathrm{~K}$ modem and a telephone link.

Each participant was asked to rate on a scale of 1-5 each of the demonstrated features of NetMeeting ${ }^{\circledR}$, according to how potentially useful they found the feature. Figure 5 shows the results of the evaluation. Ranks 1 to 5 indicate the perceived value of a feature with 1 indicating a low perceived value and 5 a high value. The "hits per rank" are the totalled numbers of respondents per index. For example, "video" has two respondents ranking it as ranks 1 or 2 , five as rank 3, and one as ranks 4 and 5 . To summarize:

- audio showed favourable results,

- video performed moderately,

- whiteboard performed well,

- text chat performed poorly,

- file transfer performed well, and

- application sharing was outstanding.

Discussions indicated that audio was (possibly obviously) useful to communicate with participants. There was, however, some confusion concerning the use of computer-based audio; most demonstrations used telephone/conference call rather than the application's audio (which was prone to feedback). Discussions also indicated that video was liked by some, but it was observed several times to be a "novelty." The information sharing applications were most popular. The ability to conveniently document shared conversations via the text chat application was well liked. The whiteboard was also liked and, in several cases, it was observed to be a convenient "brainstorming" tool. The file transfer utility was found to be useful, as it was considered helpful by some to transfer files to all participants by a click of a button, rather than 


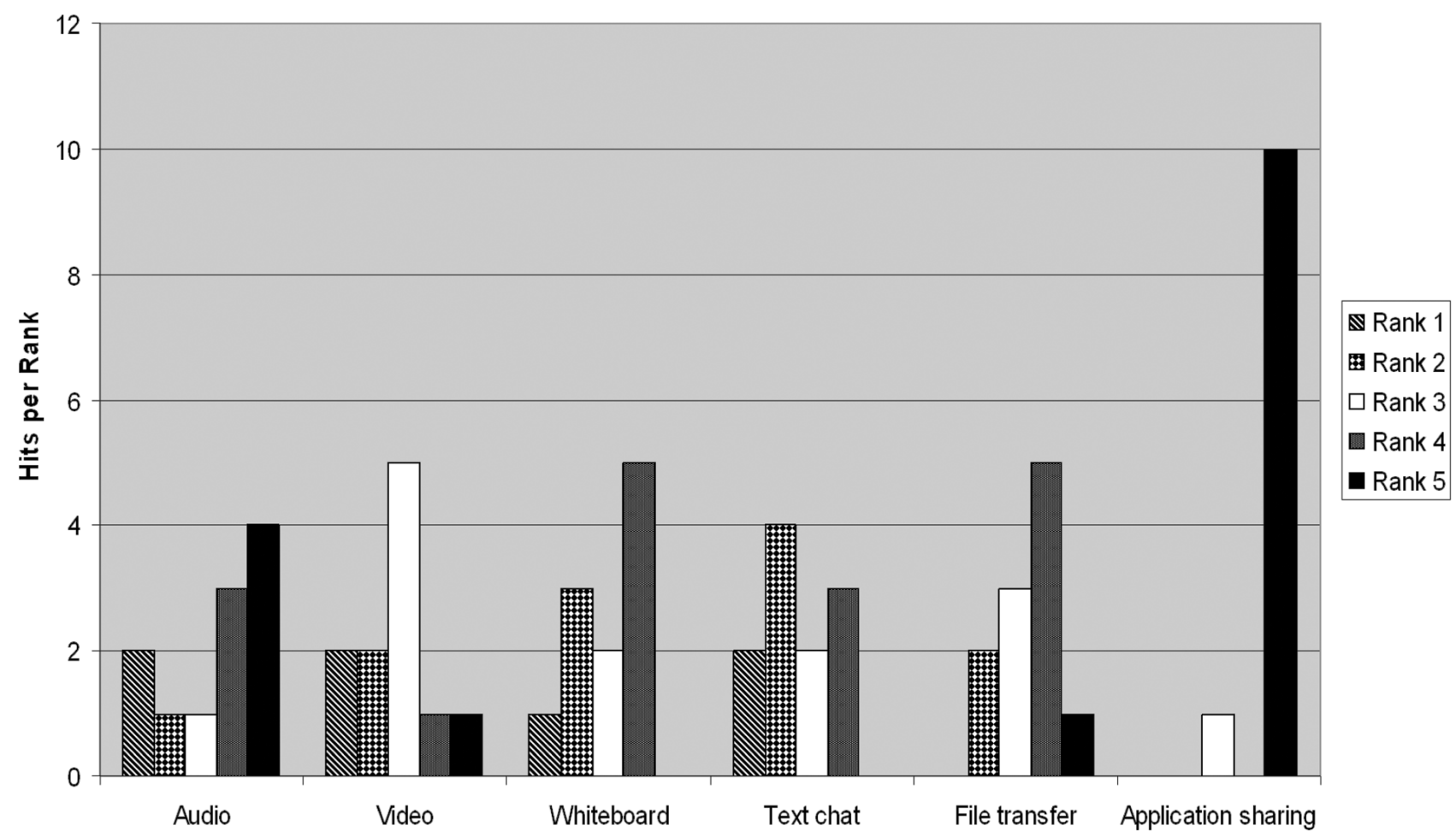

Fig. 5. NetMeeting Features by Rank.

having to use email attachments. Many different uses of application sharing were discussed and were oriented around the ability for multiple users to take control of another's application to interactively demonstrate various model features on-line.

\subsection{Stage 2}

This stage involved discussions on the use of NetMeeting ${ }^{\circledR}$ with all returnees. What these showed was that two to three months after the return the questionnaire, either the returnee did not use NetMeeting ${ }^{\circledR}$ or they were now supporting some parts of the simulation modelling task. The only major difference between the users and non-users was the amount of modelling performed by the returnee. In subsequent follow-up meetings to study the way in which NetMeeting ${ }^{\circledR}$ was being used, three industrialists were singled out as innovators in the use of NetMeeting ${ }^{\circledR}$ in their simulation modelling activities. Overall, in terms of interaction with the various roles involved in a simulation project experience with the use of this tool has seen the augmentation of regular communica- tion between the doers and the done for. Our returnees emphasised that this technology must not replace face-to-face meetings with remotely led net-conferences. However, since it appears that meetings can significantly contribute to the cost of a project, several modellers have commented on the use of net-conferencing to replace some meetings. Their innovative uses of NetMeeting ${ }^{\circledR}$ are outlined below.

Conceptual Modelling. As has been mentioned, in this activity the doers require frequent and regular contact with the done for and done with in order to understand the nature of the problem situation, to define the modelling objectives and to define the conceptual model. In the discussions specifically related to NetMeeting ${ }^{\circledR}$, the main application that has appeared is the use of the whiteboard to collaboratively map out the boundaries and details of the conceptual model. In this situation, several computers have been networked in the same room, possibly with one being linked to a projected display. A discussion takes place about the model, usually run by a facilitator, and participants draw appropriate diagrams sharing the whiteboard. This is a computerised version of 
a flip chart with the bonus of being able to import figures and diagrams and interact between parties in real time. No specific use of NetMeeting ${ }^{\circledR}$ has been identified for the done to (the providers of the data necessary for the development of the model).

Model Coding (especially white-box validation). In this application, face-to-face meetings are required to discuss whether or not a model is being coded correctly (although less than in Conceptual Modelling). Typically, the doer demonstrates the model to the done for and to the done with to determine correctness and to promote belief in the model. Several modellers are now using the application sharing feature of NetMeeting ${ }^{\circledR}$ to replace some of the meetings. This, combined with a phone call (or conference call), allows the doers to interact remotely with the done for and to the done with by allowing both parties to interact with the modelling software. In addition to this, the text chat feature has been used to document the agreement between parties that a change in the model coding has been agreed. This has been used to add to the model documentation.

Support Tasks. In addition to Conceptual Modelling and Model Coding (and Validation), NetMeeting ${ }^{\circledR}$ has found its use between the doers and an unexpected group of members of the done with. These are the support teams found in large simulation groups and simulation vendors. There are some project costs that come as a result of the need to install new simulation software (or software tools), training to use the software, and support on tool use problems (rather than on Validation). The ability to share a simulation application through NetMeeting means that simulation software can be installed remotely (in one case across two continents), can be used to augment (not replace) existing training strategies, and can make support on tool use completely remote. This point was reinforced by the insistence of one returnee requiring that the support on their simulation software was performed through NetMeeting ${ }^{\circledR}$. This has resulted in NetMeeting ${ }^{\circledR}$ being integrated in the vendor's support package and is now being roled out to their customers.

\section{Conclusions}

This paper has discussed, from the perspective of CSSM, the problem of whether or not it is possible to support human-to-human collaboration in simulation modelling through the use of commonly available groupware technology. We have identified that in a simulation modelling study, people that play different roles during a series of simulation modelling tasks, and that communication and collaboration is a key factor in the success of such a study. We have introduced the notion of groupware and its classification via a time/location matrix, and have presented NetMeeting ${ }^{\circledR}$, an example of commonly available groupware. Experiences of a successful (but limited) two stage evaluation of this type of groupware were then considered, and it was shown that, for this type of groupware at least, it is possible to support collaboration in simulation modelling. It may well be the case that the integrated nature of the groupware tool has positively biased these against other, single-featured tools. However, these results are informal in nature and we freely acknowledge that more substantial work still needs to be done (such as that based on ground breaking work performed on cognitive cueing in the early seventies $[18,19])$. Even so, these results have been successfully adopted by three major industrialists (see below for one example in the Ford Motor Company).

Some might consider it obvious that simulation modelling is a fundamentally interactive technique that will always require must communication and collaboration to be successful (or indeed possible!) However, as this paper has discussed, the type of interaction between the roles of those involved in a simulation study can vary. We consider the time/location matrix as a convenient representation that captures same and different time and location modes of working. For example, during conceptual modelling the doer and the done for will meet regularly at the same time in the same place to "brainstorm" different approaches to modelling a problem. However, if either party cannot physically attend the meeting, they can meet at the same time and in different, but predictable places (via net-conferencing groupware, for example). Between meetings, information can be shared at a different, but unpredictable time/different, but 
predictable location basis (via email, for example). Similar examples can be cited for other simulation tasks and other combinations of time and location. In other words, we suggest that the time/location matrix in conjunction with this paper's consideration of roles might be used to structure and guide thinking as to how technology (groupware) can be used to support the various tasks in simulation modelling. Additionally, organizational approaches to collaboration can also be considered. For example, Thinklets [20], effectively well-defined social protocols to describe interaction between people, can reduce the time and cost of a simulation project with and without groupware.

In conclusion, it is hoped that this paper will engender further research into CSSM though groupware and studies of a more formal nature. For more examples on the use of NetMeeting ${ }^{\circledR}$, see [21] for a study of how groupware has changed work practices in Power Train Operations in the Ford Motor Company. Specifically, this addresses the use of NetMeeting ${ }^{\circledR}$ to resolve modelling problems, to train users in software and to obtain "on-demand" vendor support via application sharing. To find out more concerning computer-to-computer collaboration in CSSM, the COTS Simulation Package Interoperability Forum (CSPIF - www.cspif.com) is currently addressing such issues [22].

\section{Acknowledgement}

This work has been partially supported by the EPSRC GROUPSIM Network (GR/N/35304). We would like to thank Neil Bowerman (Nestle UK), Simon Dennis and Ray McKirdy (BTExact) for valuable comments on this work.

\section{References}

[1] J. BANKS, Handbook of Simulation, Wiley, New York, (1998).

[2] V. HLuPIC, Simulation Software: What Users Want? Simulation, 6 (1999), pp. 362-370.

[3] K.J. Musselman, Conducting a Successful Simulation Project, Proceedings of the 1992 Winter Simulation Conference, Association for Computing Machinery, New York, NY. (1992) pp. 115-121.
[4] A.M. LAw, A Forum on Critical Issues in Simulation Modeling, Industrial Engineering, 5 (1993), pp. 32-36.

[5] S. Robinson, Successful Simulation: A Practical Approach to Simulation Projects, McGraw-Hill, Maidenhead, UK, (1994).

[6] A.M. LAW AND W.D. Kelton, Simulation Modeling and Analysis, $3^{\text {rd }}$ ed. McGraw-Hill, New York, (2000).

[7] C.B. Tilanus, O.B. DE Gans and J.K. Lenstra, Quantitative Methods in Management: Case Studies of Failures and Successes, Wiley, Chichester, UK, (1986).

[8] D.P. Slevin And J.K. PINTO, The Project Implementation Profile: New Tool for Project Managers, Project Management Journal, 4 (1986), pp. 57-70.

[9] S. Robinson, General Concepts of Quality for Discrete-Event Simulation, European Journal of Operational Research, 1 (2002), pp. 103-117.

[10] S. Robinson AND M. PIDD, Provider and Customer Expectations of Successful Simulation Projects, Journal of the Operational Research Society, 3 (1998), pp. 200-209.

[11] R.M. BELBIN, Team Roles at Work, ButterworthHeinemann, Oxford, UK, (1993).

[12] S. Platt, R. PiePe And J. Smyth, Temas: A Game to Develop Group Skills, Gower Press, Abingdon, UK, (1988).

[13] G. MitchelL, The Practice of Operational Research, Wiley, Chichester, UK, (1993).

[14] R.J. ORMEROD, Viewpoint: The Success and Failure of Methodologies - a Comment on Connell: Evaluating Soft OR, Journal of the Operational Research Society, 10 (2001), pp. 1176-1179.

[15] S. Robinson, Simulation Verification, Validation and Confidence: A Tutorial, Transactions of the Society for Computer Simulation International, 2 (1999), pp. 63-69.

[16] S. Robinson, Modes of Simulation Practice: Approaches to Business and Military Simulation, Simulation Practice and Theory, 10 (2003), pp. 513-523

[17] U.M. BORGHOFF AND J. H. SCHLICTER, Computer Supported Cooperative Work: Introduction to Distributed Applications, Springer-Verlag, Berlin, Heidelberg, Germany, (2000).

[18] A. Chapanis, R.B. OChSMan, R.N. Parrish G.D. AND WECKS, Studies in Interactive Communication I: Effects of 4 Communication Modes on the Behaviour of Teams During Co-operative Problem Solving, Human Factors, 14 (1972), pp. 487-509.

[19] A. Chapanis, R.B. OchSman, R.N. Parrish G.D. AND WECKS, Interactive Communication 2: Effects of 4 Communication Modes on Linguistic Performance of Teams During Co-operative ProblemSolving, Human Factors, 2 (1977), pp. 101-126. 
[20] E. L. SANTANen, R.O. BRIGgs AND G.-J. DE VREEDE, Causal Relationships in Creative Problem Solving: Comparing Facilitation Interventions for Ideation, Journal of Management Information Systems, 4 (2002), pp. 167-197.

[21] J. LADBROOK, AND A. JANUSZCZAK, Fords Power Train Operations - Changing the Simulation Environment, Proceedings of the 2001 Winter Simulation Conference, (2001), pp. 863-869, Association for Computing Machinery, New York

[22] S.J.E. TAYLOR, HLA-CSPIF: The High Level Architecture - COTS Simulation Package Interoperation Forum, Proceedings of the Fall 2003 Simulation Interoperability Workshop, (2003), 03F-SIW-126, Simulation Interoperability Standards Organisation, Institute for Simulation and Training, Florida

$$
\begin{array}{r}
\text { Received: July, 2004 } \\
\text { Revised: August, 2004 } \\
\text { Accepted: August, } 2004 \\
\\
\text { Contact address: } \\
\text { Simon J. E. Taylor } \\
\text { Centre for Applied Simulation Modelling } \\
\text { School of Information Systems, Computing } \\
\text { and Mathematical Sciences } \\
\text { Brunel University } \\
\text { Uxbridge } \\
\text { Middlesex, UB8 3PH } \\
\text { UK } \\
\text { e-mail: simon.taylor@brunel.ac.uk } \\
\text { Stewart Robinson } \\
\text { Warwick Business School } \\
\text { University of Warwick } \\
\text { Coventry } \\
\text { UK } \\
\text { e-mail: stewart.robinson@warwick. ac.uk } \\
\text { John Ladbrook } \\
\text { Duncton Engineering Centre } \\
\text { The Ford Motor Company } \\
\text { Basildon } \\
\text { UK } \\
\text { e-mail: jladbroo@f ord.com }
\end{array}
$$

SIMON J. E. TAYLOR is a senior lecturer at the Centre for Applied Simulation Modelling in the School of Information Systems, Computing and Mathematical Sciences, Brunel University and a visiting professor at the Parallel and Distributed Computing Centre in Nanyang Technological University (Singapore). His research interests include ICT intervention in simulation modelling, distributed simulation and simulation modelling.

STEWART ROBINSON is a senior lecturer in Operational Research at Warwick Business School in the UK. Previously employed in simulation consultancy, he supported the use of simulation in companies throughout Europe and the rest of the world. He is author/co-author of three books on simulation. His research focuses on the practice of simulation model development and use. The key areas of his interest are conceptual modelling, model validation and output analysis.

JOHN LADBROOK has worked for Ford Motor Company since 1968 where his current position is Simulation Technical Specialist. In this role he has been responsible for sponsoring many projects with various universities. He is Chairman of the Witness Automotive Special Interest Group. 